\title{
ANÁLISE COMPARATIVA DA OPINIÃO DE ENFERMEIROS DE DIFERENTES UNIDADES PSIQUIÁTRICAS SOBRE A PESSOA EM SOFRIMENTO PSÍQUICO
}

[Comparative analysis of nurses' views from different psychiatric units on an individual in psychic suffering]

RESUMO: O presente estudo mostra a opinião de enfermeiros de quatro diferentes unidades psiquiátricas sobre a pessoa em sofrimento psíquico e seu transtorno mental. Participaram desta pesquisa 15 (quinze) enfermeiros de quatro diferentes unidades psiquiátricas de assistência. Os resultados mostraram semelhanças entre as posturas adotadas por estes profissionais em face da pessoa referida, apesar de estarem inseridos em unidades com característica de trabalho distintas. Essa semelhança pode ser atribuída ao fato de que cerca de $50 \%$ (cinqüenta) desses enfermeiros são especialistas na área e estão direta ou indiretamente em contato com instituições universitárias. Com base nesses dados, concluise que, de forma geral, esses enfermeiros possuem opiniões com tendências positivas perante a pessoa em sofrimento psíquico, o que nos leva a crer que, costumeiramente, adotam posturas terapêuticas no desenvolvimento de seu trabalho.

PALAVRAS-CHAVE: enfermagem psiquiátrica, saúde mental, estresse psicológico.

\section{INTRODUÇÃO}

O desenvolvimento de abordagens terapêuticas, que possibilitaram a assistência da pessoa em sofrimento psíquico em unidades psiquiátricas em hospitais gerais, hospitais dia e núcleos de atenção psicossocial, entre outras, teve seu início na década de 50 , com o aparecimento

\footnotetext{
*Enfermeira. Especialista em Enfermagem Psiquiátrica e Saúde Mental pela Escola de Enfermagem de Ribeirão Preto da Universidade de São Paulo (EERP-USP). Mestre em Enfermagem Psiquiátrica pela EERPUSP.

${ }^{* *}$ Enfermeiro. Professor Doutor do Departamento de Enfermagem Psiquiátrica e Ciências Humanas da EERP-USP.
}

dos psicofármacos, proporcionando um controle mais eficaz dos sintomas psicóticos (AYUSO GUTIERREZ; CALVE PEREZ, 1976).

Aos psicofármacos associaram-se outras abordagens psicoterapêuticas e socioterapêuticas, levadas às instituições, cujas técnicas grupais evidenciaram maior adaptação às várias situações terapêuticas, sendo um exemplo o grupo operativo que, utilizado nas unidades como proposta de articulação e gerenciamento das atividades desenvolvidas, ofereceu aos participantes a possibilidade de explorar suas fantasias básicas, criando condições de confronto entre seu comportamento desfocado da realidade, mobilizando e rompendo as suas estruturas estereotipadas (BLAYA, 1967; PICHON RIVIÉRE, 1988).

O trabalho com atividades grupais teve seu espaço ampliado, porque possibilita atendimento de vários pacientes no mesmo período, melhora as condições básicas das citadas unidades e aliase a seus ambientes terapêuticos, que perderam, assim, a conotação de meros expectadores e ofertantes de custódia, passando a ser também instrumentos terapêuticos.

Desta forma, o ambiente terapêutico, agora com importância ímpar na assistência da pessoa em sofrimento psíquico, pode ser considerado como modelo não acima de outras técnicas terapêuticas, como a psicofarmacoterapia, a terapia individual ou grupal, mas, está hierarquicamente no mesmo nível delas, principalmente quando se leva em consideração a interação equipe/paciente; e neste aspecto há uma evidência maior da equipe de enfermagem e do enfermeiro em si, pois estão presentes o tempo todo no ambiente terapêutico fazendo parte da ecologia ambiental das unidades psiquiátricas (OSÓRIO, 1982; TAYLOR, 1992; BOTEGA; DALGALARRONDO, 1997; PEDRÃO, 
1997).

Esta particularidade confere ao enfermeiro destaque de coordenador da equipe de enfermagem, mantendo-a articulada com a equipe multiprofissional (médicos, psicólogos, assistente social, terapeuta ocupacional, etc.) onde a tomada de decisões não deve ocorrer de forma vertical, autoritária e sim horizontal, na constante busca do consenso (BOTEGA; DALGALARRONDO, 1997).

O enfermeiro, inserido nesse contexto, possui papel preponderante junto à equipe de enfermagem, e deve agir com atitudes positivas diante do paciente em sofrimento psíquico, como, por exemplo, o acolhimento, empatia e relação de ajuda e assistência humanizada na relação interpessoal, pois alguns estudos mostram tendência deste profissional em tomar atitudes autoritárias e de restrição, mais que outros profissionais, causando maior interferência na abordagem terapêutica (MEYER, 1973; KHAN, 1976; AYUSO GUTIERREZ; SAIZ RUIZ, 1978; RODRIGUES, 1983).

Outra particularidade, que a prática revela, é que nem todas as unidades ou serviços que prestam assistência psiquiátrica exigem uma formação específica ou aprimoramento em enfermagem psiquiátrica e saúde mental, necessários para o exercício das funções nesses locais. Desta forma, parte desses enfermeiros possuem apenas o conhecimento básico de enfermagem psiquiátrica e saúde mental, o que não é suficiente, visto que as exigências deste profissional, em relação ao desenvolvimento das atividades terapêuticas com a pessoa em sofrimento psíquico, a supervisão de sua equipe e a organização do ambiente terapêutico são de sua responsabilidade (KYES; HOFLING, 1985; TAYLOR, 1992).

Assim, deve-se dar atenção especial a todas as atividades que ocorrem rotineiramente nos locais que oferecem assistência psiquiátrica, pois o enfermeiro precisa de treinamento especial para ter participação efetiva. Isso pode ser obtido nos cursos de especialização em enfermagem psiquiátrica e de saúde mental, o que possibilitaria também a realização de educação em serviço, onde um enfermeiro com melhor formação e experiência teria maior facilidade para discutir conteúdos relativos aos trabalhos de saúde mental junto aos demais enfermeiros e também a toda a equipe de enfermagem, em processo contínuo.

Em relação ao trabalho realizado hoje nas unidades de saúde mental, há uma predominância nas atividades com grupos. Nas atas da Associação Brasileira de Enfermagem, Regional de Ribeirão Preto, encontram-se registros de realizações de palestras e cursos de Dinâmica de Grupo para enfermeiros na década de setenta. Outros exemplos podem ser obtidos a partir das atividades do enfermeiro de saúde pública nos serviços de puericultura e assistência às gestantes, geralmente relacionados com a dimensão educativa (MUNARI; RODRIGUES, 1997).

Especificamente na enfermagem psiquiátrica, a utilização de grupos com os mais diversos objetivos é uma constante, visando à organização do ego, a diminuição da angústia e da culpa do portador de sofrimento mental. Alguns autores salientam a questão do preparo do enfermeiro para o desenvolvimento das atividades em grupo como requisito para a sua realização, haja vista que em sua formação profissional as oportunidades de conhecimento teórico-vivencial sobre o trabalho grupal são escassas (MUNARI; RODRIGUES, 1997).

Pressupondo-se que as atitudes do enfermeiro que atua nesses grupos, em face da pessoa em sofrimento psíquico, está influenciada pelas suas opiniões a respeito da doença mental e que essas atitudes podem ser modificadas a partir de processos contínuos de educação, eis como foram estabelecidos os objetivos deste trabalho, que se resume em conhecer e analisar comparativamente a opinião de enfermeiros de quatro diferentes unidades psiquiátricas, que utilizam atividades grupais em suas modalidades terapêuticas sobre a pessoa em sofrimento psíquico.

\section{METODOLOGIA}

\subsection{SUJEITOS E LOCAL}

Participaram deste estudo quinze enfermeiros que têm em sua rotina de trabalho atividades de grupo, pertencentes a quatro unidades de assistência à pessoa portadora de transtorno mental de Ribeirão Preto: Unidade de Agudos Masculino do Hospital Santa Tereza de 
Ribeirão Preto (ST); Unidade de Psiquiatria Professor Luiz da Rocha Cerqueira do Hospital das Clínicas de Ribeirão Preto (UPHC); Hospital Dia do Hospital das Clínicas de Ribeirão Preto (HD) e Núcleo de Atenção Psicossocial da Secretaria Municipal da Saúde de Ribeirão Preto (NAPs).

\subsection{ESCALA DE AVALIAÇÃO UTILIZADA}

Foi utilizada a escala de Opiniões sobre doença mental - ODM (Anexo 1), desenvolvida por Cohen \& Struening (1962), traduzida e validada por Rodrigues (1992), composta de 51 afirmações do tipo LIKERT, com 6 opções de respostas, variando segundo uma seqüência progressiva de seis pontos de concordância, desde "concordo totalmente" até "discordo totalmente". Essas afirmações foram agrupadas em sete fatores, denominados por Rodrigues (1992), na forma que se lê em seguida.

Autoritarismo. Reflete a perspectiva de que o doente mental necessita ser isolado de outros pacientes, permanecendo sob portas trancadas e vigilância. Contém o conceito da irrecuperabilidade pessoal e social do doente e a idéia de sua periculosidade. Neste fator estão incluídas nove afirmações.

Benevolência. Traduz a visão de que o doente mental, devido à sua infelicidade, deve ser amparado por meio de protecionismo bondoso e paternalista, com base em cuidados, atenção pessoal e conforto material. Neste fator estão incluídas cinco afirmações.

Ideologia da higiene mental. Representa a idéia de que o doente mental é uma pessoa semelhante às pessoas normais, com diferenças quantitativas, porém não qualitativas. Podem desempenhar atividades especializadas e até cuidar de crianças. Neste fator estão incluídas onze afirmações.

Restrição social. Traduz a doença mental como uma espécie de defeito hereditário, completamente diferente de outras doenças, cujo portador pode contaminar a família e a sociedade, devendo, portanto, ser protegidas por meio de restrição dos direitos pessoais e sociais do paciente, mesmo após a hospitalização. Neste fator estão incluídas sete afirmações.

Etiologia interpessoal. Explica a doença mental como originária de vivências interpessoais, com ênfase para a interação com figuras parentais. Neste fator estão incluídas seis afirmações.

Etiologia de esforço mental. Reflete a idéia de que a doença mental se origina de "excessivo esforço cerebral" pelo trabalho intelectual exagerado, por pensar demais ou por ter pensamentos negativos. Neste fator estão incluídas oito afirmações.

Visão minoritária. Traduz o conceito de que o doente mental, por ser muito diferente das pessoas consideras normais, pode ser facilmente reconhecido em um agrupamento humano, principalmente pela sua aparência externa. Neste fator estão incluídas cinco afirmações.

\subsection{PROCEDIMENTO}

\subsubsection{Aplicação da ODM}

Inicialmente, foi feito contato com as instituições envolvidas no estudo para a devida autorização. O projeto do presente estudo foi avaliado e aprovado pelo Comitê de Ética em Pesquisa Envolvendo Seres Humanos do Hospital das Clínicas da Faculdade de Medicina de Ribeirão Preto da Universidade de São Paulo. Foram convidados a responder a ODM todos os enfermeiros envolvidos em atividades de grupo das unidades psiquiátricas escolhidas para o desenvolvimento do estudo. Os quinze enfermeiros participantes assinaram termo de consentimento livre e esclarecido dos sujeitos da pesquisa.

\subsubsection{Análise dos Resultados}

Para contagem dos pontos obtidos com a aplicação da ODM, foram utilizadas fórmulas estabelecidas por Struening \& Cohen (1963), obtendo-se assim os escores fatoriais brutos para cada enfermeiro, nos sete fatores desta escala.

Pela dificuldade em trabalhar com esses escores fatoriais, tendo em vista que o número de itens difere para cada fator, foi necessário sua transformação para um sistema que permitisse uma comparação padrão.

Para isso foi utilizado o sistema "Sten" 
(escores Sten), que se mostra adequado pois proporciona uma comparação padrão entre os fatores da escala referida, com variação entre $1 \mathrm{e}$ 10, média 5,5 e um desvio padrão igual a 0,5 (CANFIELD, 1951). As vantagens da utilização deste sistema foram amplamente discutidas por Lyman (1953). Procedimento idêntico foi utilizado também por Rodrigues (1992).

Desta, forma foi possível a análise dos resultados por meio dos escores médios pelos sujeitos de cada unidade, participantes deste estudo, para cada um dos sete fatores da ODM, que permitiu a discussão e considerações sobre as opiniões destes enfermeiros em face da pessoa em sofrimento psíquico.

\section{RESULTADOS}

O Quadro 1 (em anexo) mostra características dos sujeitos participantes do estudo, relativas à idade (média), tempo de formação profissional (médio), tempo em que atua na área (médio) e curso de pós-graduação lato sensu e stricto sensu.

A Figura 1 (anexo) retrata a opinião dos enfermeiros das quatro Unidades Psiquiátricas estudadas, que utilizam atividades grupais em suas modalidades terapêuticas sobre a pessoa em sofrimento psíquico em valores sten.

Com referência ao autoritarismo, observa-se que os enfermeiros do HD apresentam opiniões que refletem menor índice encontrado de autoritarismo, contra o maior índice nas opiniões de enfermeiros do NAPs. Os enfermeiros do UPHC e do ST apresentam índices lineares.

Sobre a benevolência, observa-se uma seqüência lógica no maior índice obtido, novamente pelo NAPs, sendo a benevolência definida não como abordagem terapêutica embasada na compreensão, mas como nos mostra Rodrigues (1992), um protecionismo bondoso, paternalista e caritativo, sendo portanto, opinião com conteúdo autoritário.

Sobre a ideologia da higiene mental, obtiveram-se índices elevados na opinião dos enfermeiros do HD e NAPs, pois este fator, diferentemente dos anteriores, retrata as mudanças institucionais vividas hoje nesses serviços, não dependendo de mudanças internas, atitudes pessoais, senão de uma ideologia normatizada pela instituição.

Com respeito à restrição social, observa-se certa horizontalidade nos índices obtidos pelo HD, HC e ST, que são instituições de caráter fechado. Em contrapartida, o menor índice obtido foi dos enfermeiros do NAPs, que é um modelo mais recente no que se refere à reforma psiquiátrica.

No que concerne à etiologia interpessoal, que trata da perspectiva da doença mental, por meio das vivências interpessoais, cujas interações parentais são muito importantes, os enfermeiros das quatro unidades pesquisadas apresentam opiniões semelhantes, mas no geral acreditam que os transtornos mentais têm menor origem nessas vivências.

Relativamente à etiologia de esforço mental, a falta de controle consciente sobre as emoções proporciona maior probabilidade à doença mental. Neste fator encontra-se a influência de uma carga negativa e autoritária, retratando novamente valores culturais dos sujeitos estudados (RODRIGUES, 1983), menos presente nos sujeitos do HD.

Quanto à visão minoritária que diz que a pessoa em sofrimento psíquico pode ser facilmente diferenciada das pessoas tidas como normais, principalmente quanto a sua aparência externa, temos opiniões mais discriminativas em relação a esta pessoa. Apareceram índices baixos para os enfermeiros das unidades pesquisadas.

\section{DISCUSSÃO}

As unidades psiquiátricas que serviram de local para o desenvolvimento deste estudo foram criadas há mais de vinte anos, com exceção do NAPs, que é o mais novo, criado em 1995. Essas unidades fazem parte da rede de assistência psiquiátrica de uma cidade, centro de uma região desenvolvida, de um país que possui enormes contrastes socioeconômicos. Desta forma, atrai pessoas que vêm em busca de trabalho e com perspectivas de melhor qualidade de vida; mas aqui chegando defrontam-se com uma realidade diferente daquela que imaginavam, porquanto, mesmo sendo região promissora, é muito hostil em relação ao acolhimento de pessoas advindas de outros centros, tendo falta de oportunidades 
até mesmo para a sua própria população. Isso se justifica pelo fato de que a sua economia não tem base na industrialização, que daria oportunidade a uma mão-de-obra mais especializada, e sim no comércio que tem exigência menor com relação a especialidades.

Por ser uma região servida de vários centros universitários, oferece uma variedade de cursos e especializações e, em particular, no que diz respeito à área de Enfermagem Psiquiátrica e Saúde Mental, cujos profissionais têm oportunidades de se especializar e de estar continuamente atualizados com relação à sua área específica. Isso pode ser notado nos sujeitos deste estudo que, dos quinze participantes, sete são especialistas na área e três deles têm até curso de pós-graduação stricto sensu.

Ainda sobre as unidades pesquisadas, todas têm suas particularidades, diferenciando-se entre si. Duas delas são unidades fechadas e assistem os pacientes em períodos integral, na fase aguda do transtorno psíquico. As outras duas têm semelhança nos seus objetivos, principalmente de ressocialização. Diferem com relação ao grau de comprometimento do portador de transtorno mental que assistem e também na forma de abordagem, pois em uma delas o usuário é tratado em regime de semi-internação, estruturando-se para um convívio familiar e social melhor; a outra, mais aberta, atende ao usuário mais estruturado; a sua permanência não caracteriza uma semiinternação, mas um convívio em que ele possa desenvolver-se no sentido integrativo, trabalhando seu potencial para um autocontrole de seu sofrer psíquico e tornar-se produtivo.

Portanto, pelas particularidades dessas unidades, esperava-se diferenças nas opiniões dos enfermeiros sujeitos deste estudo. No entanto os resultados mostraram semelhanças, até certo ponto surpreendentes. Por exemplo, esperava-se que os enfermeiros de unidades mais fechadas tivessem posturas mais autoritárias, restritivas e discriminativas, devido a estarem inseridos em ambientes mais controlados, até mesmo por normas institucionais. Suas posturas se assemelharam às dos enfermeiros de unidades mais abertas, sendo em algumas delas mais positivas.

Por outro lado, algumas opiniões com conteúdo autoritário são apresentadas em um local relativamente novo, onde se pressupõe que sua equipe e sua rotina terapêutica estejam em formação e estruturando-se para desempenhar seu papel.

Opiniões sobre as atividades que o portador de doença mental pode desenvolver, no sentido mais elaborado ou de grande responsabilidade, foram mais expressivas nos serviços mais abertos. Isso se justifica pelo fato de os locais fechados lidarem com estas pessoas, quando elas estão na fase crítica de sua doença.

\section{CONCLUSÃO}

As unidades onde o estudo foi realizado apresentaram particularidades que possibilitaram conhecer as opiniões de enfermeiros sobre a pessoa em sofrimento psíquico, inserida em diversas modalidades de assistência psiquiátrica.

A cidade onde as unidades pesquisadas se localizam oferece oportunidades para os profissionais dessa área se especializarem e se aprimorarem. No estudo, em torno de $50 \%$ dos sujeitos são especialistas, mestre e/ou doutores, o que influencia favoravelmente nas opiniões sobre a doença mental, pois o enfermeiro que ainda não tem formação específica tem grande chance de trabalhar ao lado de alguém que já buscou esta formação.

Partiu-se do pressuposto de que as opiniões dos enfermeiros inseridos em unidades de assistência psiquiátrica distintas sobre a pessoa em sofrimento psíquico, seriam diferentes.

No entanto os resultados mostraram que as opiniões dos enfermeiros pesquisados sobre a doença mental, nas diferentes unidades, são mais semelhantes do que se esperava.

As semelhanças apresentadas se justificam pelo fato de os enfermeiros, sujeitos do estudo, estarem próximos, de uma forma ou de outra, de um centro universitário, o que possibilita também o seu contato com professores e alunos em momentos de suas atividades teórico-práticas nessas instituições.

Em conclusão, o estudo mostrou que os enfermeiros envolvidos apresentam um perfil de opiniões com tendência positiva sobre o doente mental, com poucas diferenças entre si, o que leva a crer que estes profissionais possuem, em geral, posturas terapêuticas no trato deste paciente. 


\section{ANEXOS}

FIGURA 1: OPINIÕES DE ENFERMEIROS DAS QUATRO UNIDADES PSIQUIÁTRICAS ESTUDADAS SOBRE AS PESSOAS EM SOFRIMENTO PSÍQUICO

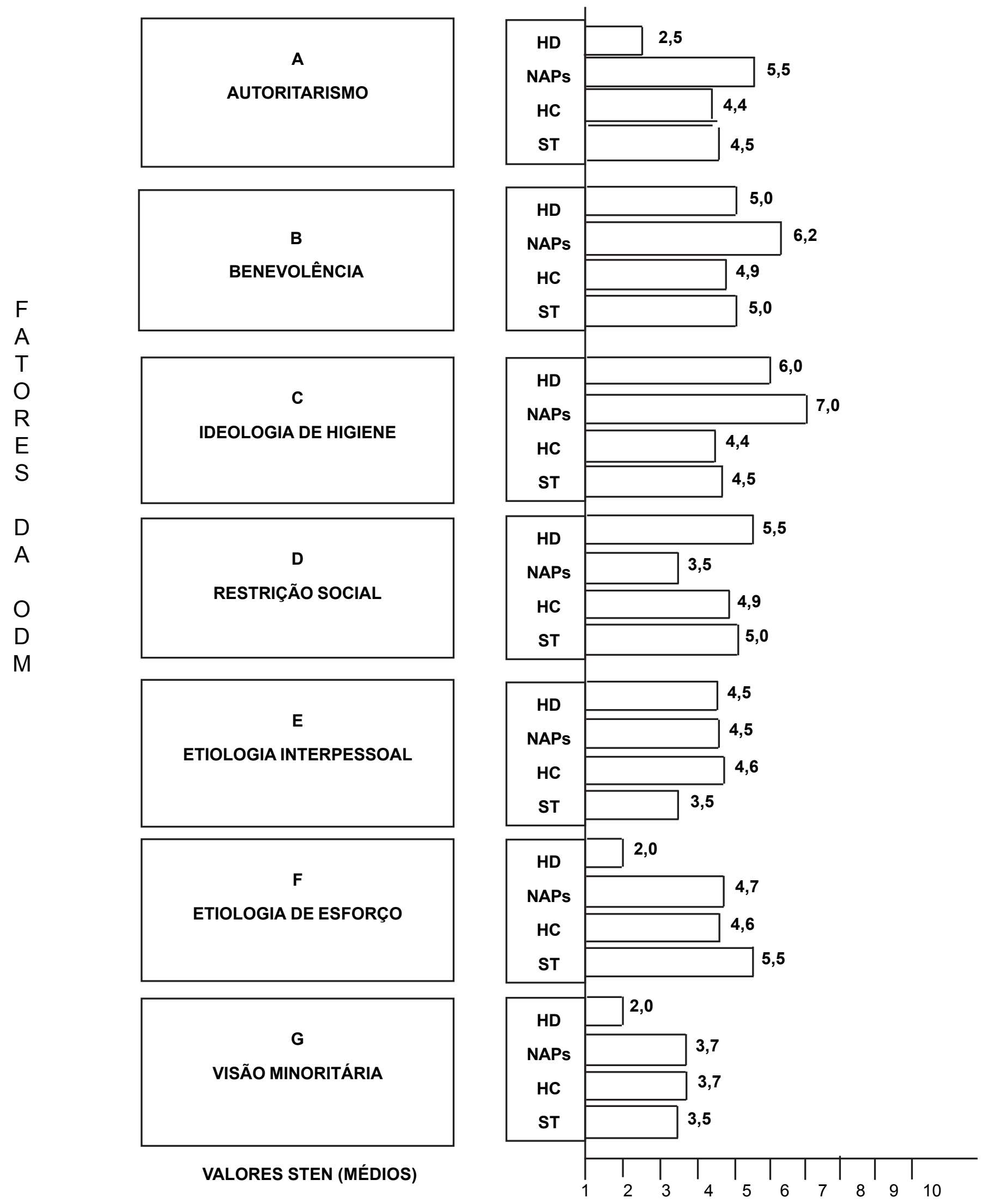


QUADRO 1: CARACTERÍSTICAS DOS ENFERMEIROS PARTICIPANTES DO ESTUDO DAS QUATRO UNIDADES

\begin{tabular}{|c|c|c|c|c|c|c|}
\hline $\begin{array}{c}\text { Características } \\
\text { Unidades }\end{array}$ & $\begin{array}{c}\text { Participantes } \\
\text { do estudo }\end{array}$ & Idade média (anos) & $\begin{array}{c}\text { Tempo de } \\
\text { formação } \\
\text { (média) }\end{array}$ & $\begin{array}{c}\text { Tempo de } \\
\text { atuação na área }\end{array}$ & $\begin{array}{c}\text { Enfermeiros } \\
\text { especialistas }\end{array}$ & $\begin{array}{c}\text { Enfermeiros } \\
\text { mestres e doutores }\end{array}$ \\
\hline HD & 2 & 34,5 & 11 & 10,5 & - & \\
\hline NAPs & 4 & 40 & 13,2 & 9,8 & 3 & 3 \\
\hline UPHC & 7 & 39,4 & 13,4 & 12,7 & - & 3 \\
\hline ST & 2 & 37 & 9,5 & 6 & - & 1 \\
\hline
\end{tabular}

\section{OPINIÕES SOBRE A DOENÇA MENTAL}

\section{1 - Dados pessoais}

a) Tempo de formação:

b) Idade:

c) Tempo de atuação em Enfermagem psiquiátrica:

d) Titulação:

\section{2 - Opiniões sobre a doença mental}

\section{INSTRUÇÕES}

As afirmações que se seguem, a partir da próxima página, são opiniões ou idéias sobre a doença e o doente mental. Entenda por doença mental, todos os tipos de doenças que levam à internação do paciente em um hospital psiquiátrico ou que exige assistência freqüente em algum serviço psiquiátrico, ou que faz seguimento freqüente em algum serviço psiquiátrico.

As opiniões são extremamente variáveis quanto a esses aspectos. Assim, muitas pessoas concordarão com várias das afirmações seguintes, enquanto que outras tantas discordarão das mesmas. Para o nosso trabalho é importante saber a sua maneira de pensar e, dessa forma, pedimos que siga as seguintes instruções:

Cada uma das afirmações é acompanhada pelas seguintes alternativas:

\begin{tabular}{|c|c|c|c|c|c|}
\hline $\begin{array}{c}\text { Concordo } \\
\text { totalmente }\end{array}$ & Concordo & $\begin{array}{c}\text { Em dúvida, mas provavelmente } \\
\text { concordo }\end{array}$ & $\begin{array}{c}\text { Em dúvida, mas provavelmente } \\
\text { discordo }\end{array}$ & $\begin{array}{c}\text { Discordo } \\
\text { totalmente }\end{array}$ & \begin{tabular}{c} 
Discordo \\
\hline 1
\end{tabular} \\
\hline 1 & 3 & 4 & 6 \\
\hline
\end{tabular}

Solicitamos que você assinale com um $X$ sobre o quadro que corresponde à alternativa que mais se aproxima daquilo que pensa sobre a afirmação. Esteja certo de que muitos profissionais afins concordarão com a sua escolha. Não existem alternativas certas ou erradas. Estamos interessados apenas em sua opinião. É muito importante que você responda todos os itens.

1. O esgotamento nervoso geralmente ocorre quando as pessoas trabalham demais.

\begin{tabular}{|c|c|c|c|c|c|}
\hline $\begin{array}{c}\text { Concordo } \\
\text { totalmente }\end{array}$ & Concordo & $\begin{array}{c}\text { Em dúvida, mas provavelmente } \\
\text { concordo }\end{array}$ & $\begin{array}{c}\text { Em dúvida, mas provavelmente } \\
\text { discordo }\end{array}$ & $\begin{array}{c}\text { Discordo } \\
\text { totalmente }\end{array}$ \\
\hline 1 & 2 & 3 & 4 & 6 & 5 \\
\hline
\end{tabular}

2. A doença mental é uma doença como outra qualquer.

\begin{tabular}{|c|c|c|c|c|c|}
\hline $\begin{array}{c}\text { Concordo } \\
\text { totalmente }\end{array}$ & Concordo & $\begin{array}{c}\text { Em dúvida, mas provavelmente } \\
\text { concordo }\end{array}$ & $\begin{array}{c}\text { Em dúvida, mas provavelmente } \\
\text { discordo }\end{array}$ & $\begin{array}{c}\text { Discordo } \\
\text { totalmente }\end{array}$ & 4 \\
\hline 1 & 2 & 3 & 4 & 6 \\
\hline
\end{tabular}

3. A maioria dos pacientes de hospitais psiquiátrica não são perigosos.

\begin{tabular}{|c|c|c|c|c|c|}
\hline $\begin{array}{c}\text { Concordo } \\
\text { totalmente }\end{array}$ & Concordo & $\begin{array}{c}\text { Em dúvida, mas provavelmente } \\
\text { concordo }\end{array}$ & $\begin{array}{c}\text { Em dúvida, mas provavelmente } \\
\text { discordo }\end{array}$ & $\begin{array}{c}\text { Discordo } \\
\text { totalmente }\end{array}$ \\
\hline 1 & 2 & 3 & 4 & 5 & 5 \\
\hline
\end{tabular}

4. Ainda que os pacientes possam ter um aspecto sadio após terem recebido alta de um hospital psiquiátrico, eles não deveriam ter permissão para se casar.

\begin{tabular}{|c|c|c|c|c|c|}
\hline $\begin{array}{c}\text { Concordo } \\
\text { totalmente }\end{array}$ & Concordo & $\begin{array}{c}\text { Em dúvida, mas provavelmente } \\
\text { concordo }\end{array}$ & $\begin{array}{c}\text { Em dúvida, mas provavelmente } \\
\text { discordo }\end{array}$ & $\begin{array}{c}\text { Discordo } \\
\text { totalmente }\end{array}$ & \begin{tabular}{c} 
Discordo \\
\hline 1
\end{tabular} \\
\hline 1 & 3 & 4 & 6 & 5 \\
\hline
\end{tabular}

5. Se os pais amassem mais os seus filhos, haveria menos doenças mentais.

\begin{tabular}{|c|c|c|c|c|c|}
\hline $\begin{array}{c}\text { Concordo } \\
\text { totalmente }\end{array}$ & Concordo & $\begin{array}{c}\text { Em dúvida, mas provavelmente } \\
\text { concordo }\end{array}$ & $\begin{array}{c}\text { Em dúvida, mas provavelmente } \\
\text { discordo }\end{array}$ & $\begin{array}{c}\text { Discordo } \\
\text { totalmente }\end{array}$ \\
\hline 1 & 2 & 3 & 4 & 6 & 5 \\
\hline
\end{tabular}


6. É fácil de se reconhecer alguém que já teve uma doença mental grave.

\begin{tabular}{|c|c|c|c|c|c|}
\hline $\begin{array}{c}\text { Concordo } \\
\text { totalmente }\end{array}$ & Concordo & $\begin{array}{c}\text { Em dúvida, mas provavelmente } \\
\text { concordo }\end{array}$ & $\begin{array}{c}\text { Em dúvida, mas provavelmente } \\
\text { discordo }\end{array}$ & $\begin{array}{c}\text { Discordo } \\
\text { totalmente }\end{array}$ & \begin{tabular}{c} 
Discordo \\
\hline 1
\end{tabular} \\
\hline
\end{tabular}

7. As pessoas que são mentalmente doentes deixam-se dominar pelas emoções; as pessoas normais controlam-nas.

\begin{tabular}{|c|c|c|c|c|c|}
\hline $\begin{array}{c}\text { Concordo } \\
\text { totalmente }\end{array}$ & Concordo & $\begin{array}{c}\text { Em dúvida, mas provavelmente } \\
\text { concordo }\end{array}$ & $\begin{array}{c}\text { Em dúvida, mas provavelmente } \\
\text { discordo }\end{array}$ & $\begin{array}{c}\text { Discordo } \\
\text { totalmente }\end{array}$ & \begin{tabular}{c} 
Discordo \\
\hline 1
\end{tabular} \\
\hline 1 & 3 & 4 & 6 & 5 \\
\hline
\end{tabular}

8. As pessoas que já foram pacientes em hospitais psiquiátricos não são mais perigosas do que uma pessoa comum.

\begin{tabular}{|c|c|c|c|c|c|}
\hline $\begin{array}{c}\text { Concordo } \\
\text { totalmente }\end{array}$ & Concordo & $\begin{array}{c}\text { Em dúvida, mas provavelmente } \\
\text { concordo }\end{array}$ & $\begin{array}{c}\text { Em dúvida, mas provavelmente } \\
\text { discordo }\end{array}$ & $\begin{array}{c}\text { Discordo } \\
\text { totalmente }\end{array}$ & 4 \\
\hline 1 & 2 & 3 & 4 & 5 \\
\hline
\end{tabular}

9. Quando alguém tem um problema ou uma preocupação, é melhor não pensar no assunto e manter-se ocupado com coisas mais agradáveis.

\begin{tabular}{|c|c|c|c|c|c|}
\hline $\begin{array}{c}\text { Concordo } \\
\text { totalmente }\end{array}$ & Concordo & $\begin{array}{c}\text { Em dúvida, mas provavelmente } \\
\text { concordo }\end{array}$ & $\begin{array}{c}\text { Em dúvida, mas provavelmente } \\
\text { discordo }\end{array}$ & $\begin{array}{c}\text { Discordo } \\
\text { totalmente }\end{array}$ & \begin{tabular}{c} 
Discordo \\
\hline 1
\end{tabular} \\
\hline
\end{tabular}

10. Muitas pessoas tornam-se mentalmente doentes para fugir dos problemas difíceis da vida cotidiana, apesar de geralmente não estarem conscientes disto.

\begin{tabular}{|c|c|c|c|c|c|}
\hline $\begin{array}{c}\text { Concordo } \\
\text { totalmente }\end{array}$ & Concordo & $\begin{array}{c}\text { Em dúvida, mas provavelmente } \\
\text { concordo }\end{array}$ & $\begin{array}{c}\text { Em dúvida, mas provavelmente } \\
\text { discordo }\end{array}$ & $\begin{array}{c}\text { Discordo } \\
\text { totalmente }\end{array}$ \\
\hline 1 & 2 & 3 & 4 & 5 & 5 \\
\hline
\end{tabular}

11. Existe alguma coisa nos doentes mentais que torna fácil distingui-los das pessoas normais.

\begin{tabular}{|c|c|c|c|c|c|}
\hline $\begin{array}{c}\text { Concordo } \\
\text { totalmente }\end{array}$ & Concordo & $\begin{array}{c}\text { Em dúvida, mas provavelmente } \\
\text { concordo }\end{array}$ & $\begin{array}{c}\text { Em dúvida, mas provavelmente } \\
\text { discordo }\end{array}$ & $\begin{array}{c}\text { Discordo } \\
\text { totalmente }\end{array}$ \\
\hline 1 & 2 & 3 & 4 & 5 & 5 \\
\hline
\end{tabular}

12. Não se deve rir de pacientes nos hospitais psiquiátricos, mesmo que eles se comportem de forma cômica.

\begin{tabular}{|c|c|c|c|c|c|}
\hline $\begin{array}{c}\text { Concordo } \\
\text { totalmente }\end{array}$ & Concordo & $\begin{array}{c}\text { Em dúvida, mas provavelmente } \\
\text { concordo }\end{array}$ & $\begin{array}{c}\text { Em dúvida, mas provavelmente } \\
\text { discordo }\end{array}$ & $\begin{array}{c}\text { Discordo } \\
\text { totalmente }\end{array}$ \\
\hline 1 & 2 & 3 & 4 & 5 & 5 \\
\hline
\end{tabular}

13. A maioria dos pacientes psiquiátricos deseja trabalhar.

\begin{tabular}{|c|c|c|c|c|c|}
\hline $\begin{array}{l}\text { Concordo } \\
\text { totalmente }\end{array}$ & Concordo & $\begin{array}{l}\text { Em dúvida, mas provavelmente } \\
\text { concordo }\end{array}$ & $\begin{array}{l}\text { Em dúvida, mas provavelmente } \\
\text { discordo }\end{array}$ & Discordo & $\begin{array}{l}\text { Discordo } \\
\text { totalmente }\end{array}$ \\
\hline 1 & 2 & 3 & 4 & 5 & 6 \\
\hline
\end{tabular}

14. Não se deve permitir que as crianças visitem seus pais internados em hospitais psiquiátricos.

\begin{tabular}{|c|c|c|c|c|c|}
\hline $\begin{array}{c}\text { Concordo } \\
\text { totalmente }\end{array}$ & Concordo & $\begin{array}{c}\text { Em dúvida, mas provavelmente } \\
\text { concordo }\end{array}$ & $\begin{array}{c}\text { Em dúvida, mas provavelmente } \\
\text { discordo }\end{array}$ & $\begin{array}{c}\text { Discordo } \\
\text { totalmente }\end{array}$ \\
\hline 1 & 2 & 3 & 4 & 5 & \\
\hline
\end{tabular}

15. As pessoas bem sucedidas no trabalho raramente tornam-se mentalmente doentes.

\begin{tabular}{|c|c|c|c|c|c|}
\hline $\begin{array}{c}\text { Concordo } \\
\text { totalmente }\end{array}$ & Concordo & $\begin{array}{c}\text { Em dúvida, mas provavelmente } \\
\text { concordo }\end{array}$ & $\begin{array}{c}\text { Em dúvida, mas provavelmente } \\
\text { discordo }\end{array}$ & $\begin{array}{c}\text { Discordo } \\
\text { totalmente }\end{array}$ \\
\hline 1 & 2 & 3 & 4 & 5 & \\
\hline
\end{tabular}

16. As pessoas não se tornariam mentalmente doentes se evitassem pensamentos negativos.

\begin{tabular}{|c|c|c|c|c|c|}
\hline $\begin{array}{c}\text { Concordo } \\
\text { totalmente }\end{array}$ & Concordo & $\begin{array}{c}\text { Em dúvida, mas provavelmente } \\
\text { concordo }\end{array}$ & $\begin{array}{c}\text { Em dúvida, mas provavelmente } \\
\text { discordo }\end{array}$ & $\begin{array}{c}\text { Discordo } \\
\text { totalmente }\end{array}$ \\
\hline 1 & 2 & 3 & 4 & 6 \\
\hline
\end{tabular}

17. Os pacientes em hospitais psiquiátricos são, sob muitos aspectos, como crianças.

\begin{tabular}{|c|c|c|c|c|c|}
\hline $\begin{array}{c}\text { Concordo } \\
\text { totalmente }\end{array}$ & Concordo & $\begin{array}{c}\text { Em dúvida, mas provavelmente } \\
\text { concordo }\end{array}$ & $\begin{array}{c}\text { Em dúvida, mas provavelmente } \\
\text { discordo }\end{array}$ & $\begin{array}{c}\text { Discordo } \\
\text { totalmente }\end{array}$ & 4 \\
\hline 1 & 2 & 3 & 4 & 6 \\
\hline
\end{tabular}

18. Deveriam ser liberadas mais verbas federais para o cuidado e tratamento de pessoas com doença mental grave.

\begin{tabular}{|c|c|c|c|c|c|}
\hline $\begin{array}{c}\text { Concordo } \\
\text { totalmente }\end{array}$ & Concordo & $\begin{array}{c}\text { Em dúvida, mas provavelmente } \\
\text { concordo }\end{array}$ & $\begin{array}{c}\text { Em dúvida, mas provavelmente } \\
\text { discordo }\end{array}$ & $\begin{array}{c}\text { Discordo } \\
\text { totalmente }\end{array}$ & \begin{tabular}{c} 
Discordo \\
\hline 1
\end{tabular} \\
\hline 1 & 3 & 4 & 6 & 5 \\
\hline
\end{tabular}


19. Um paciente psiquiátrico é completamente diferente de outros, como por exemplo, dos pacientes cardíacos.

\begin{tabular}{|c|c|c|c|c|c|}
\hline $\begin{array}{c}\text { Concordo } \\
\text { totalmente }\end{array}$ & Concordo & $\begin{array}{c}\text { Em dúvida, mas provavelmente } \\
\text { concordo }\end{array}$ & $\begin{array}{c}\text { Em dúvida, mas provavelmente } \\
\text { discordo }\end{array}$ & $\begin{array}{c}\text { Discordo } \\
\text { totalmente }\end{array}$ & \begin{tabular}{c} 
Discordo \\
\hline 1
\end{tabular} \\
\hline
\end{tabular}

20. Os pacientes psiquiátricos são provenientes de lares onde os pais pouco se interessavam pelos filhos.

\begin{tabular}{|c|c|c|c|c|c|}
\hline $\begin{array}{c}\text { Concordo } \\
\text { totalmente }\end{array}$ & Concordo & $\begin{array}{c}\text { Em dúvida, mas provavelmente } \\
\text { concordo }\end{array}$ & $\begin{array}{c}\text { Em dúvida, mas provavelmente } \\
\text { discordo }\end{array}$ & $\begin{array}{c}\text { Discordo } \\
\text { totalmente }\end{array}$ \\
\hline 1 & 2 & 3 & 4 & 6 & 5 \\
\hline
\end{tabular}

21. Pessoas portadoras de doença mental nunca devem ser tratadas no mesmo hospital que pessoas com doenças físicas.

\begin{tabular}{|c|c|c|c|c|c|}
\hline $\begin{array}{c}\text { Concordo } \\
\text { totalmente }\end{array}$ & Concordo & $\begin{array}{c}\text { Em dúvida, mas provavelmente } \\
\text { concordo }\end{array}$ & $\begin{array}{c}\text { Em dúvida, mas provavelmente } \\
\text { discordo }\end{array}$ & $\begin{array}{c}\text { Discordo } \\
\text { totalmente }\end{array}$ \\
\hline 1 & 2 & 3 & 4 & 6 & 5 \\
\hline
\end{tabular}

22. Qualquer pessoa que firmemente tenta progredir merece o respeito alheio.

\begin{tabular}{|c|c|c|c|c|c|}
\hline $\begin{array}{c}\text { Concordo } \\
\text { totalmente }\end{array}$ & Concordo & $\begin{array}{c}\text { Em dúvida, mas provavelmente } \\
\text { concordo }\end{array}$ & $\begin{array}{c}\text { Em dúvida, mas provavelmente } \\
\text { discordo }\end{array}$ & $\begin{array}{c}\text { Discordo } \\
\text { totalmente }\end{array}$ \\
\hline 1 & 2 & 3 & 4 & 5 & \\
\hline
\end{tabular}

23. Se nossos hospitais psiquiátricos tivessem um número suficiente de médicos, enfermeiros e auxiliares bem treinados, muitos pacientes recuperarse-iam a ponto de poder viver fora do hospital.

\begin{tabular}{|c|c|c|c|c|c|}
\hline $\begin{array}{c}\text { Concordo } \\
\text { totalmente }\end{array}$ & Concordo & $\begin{array}{c}\text { Em dúvida, mas provavelmente } \\
\text { concordo }\end{array}$ & $\begin{array}{c}\text { Em dúvida, mas provavelmente } \\
\text { discordo }\end{array}$ & $\begin{array}{c}\text { Discordo } \\
\text { totalmente }\end{array}$ & \begin{tabular}{c} 
Discordo \\
\hline 1
\end{tabular} \\
\hline 1 & 3 & 4 & 6 \\
\hline
\end{tabular}

24. Uma mulher é insensata quando se casa com um homem que teve uma doença mental grave, mesmo que ele aparentemente esteja totalmente recuperado.

\begin{tabular}{|c|c|c|c|c|c|}
\hline $\begin{array}{c}\text { Concordo } \\
\text { totalmente }\end{array}$ & Concordo & $\begin{array}{c}\text { Em dúvida, mas provavelmente } \\
\text { concordo }\end{array}$ & $\begin{array}{c}\text { Em dúvida, mas provavelmente } \\
\text { discordo }\end{array}$ & $\begin{array}{c}\text { Discordo } \\
\text { totalmente }\end{array}$ \\
\hline 1 & 2 & 3 & 4 & 6 \\
\hline
\end{tabular}

25. Se filhos de pais mentalmente doentes fossem criados por um casal normal, provavelmente não se tornariam doentes mentais.

\begin{tabular}{|c|c|c|c|c|c|}
\hline $\begin{array}{c}\text { Concordo } \\
\text { totalmente }\end{array}$ & Concordo & $\begin{array}{c}\text { Em dúvida, mas provavelmente } \\
\text { concordo }\end{array}$ & $\begin{array}{c}\text { Em dúvida, mas provavelmente } \\
\text { discordo }\end{array}$ & $\begin{array}{c}\text { Discordo } \\
\text { totalmente }\end{array}$ \\
\hline 1 & 2 & 3 & 4 & 6 & 5 \\
\hline
\end{tabular}

26. As pessoas que já foram pacientes em um hospital psiquiátrico jamais serão como antes.

\begin{tabular}{|c|c|c|c|c|c|}
\hline $\begin{array}{c}\text { Concordo } \\
\text { totalmente }\end{array}$ & Concordo & $\begin{array}{c}\text { Em dúvida, mas provavelmente } \\
\text { concordo }\end{array}$ & $\begin{array}{c}\text { Em dúvida, mas provavelmente } \\
\text { discordo }\end{array}$ & $\begin{array}{c}\text { Discordo } \\
\text { totalmente }\end{array}$ \\
\hline 1 & 2 & 3 & 4 & 6 \\
\hline
\end{tabular}

27. Muitos pacientes psiquiátricos são capazes de desempenhar um trabalho especializado, mesmo sendo, em alguns aspectos, muito perturbados mentalmente.

\begin{tabular}{|c|c|c|c|c|c|}
\hline $\begin{array}{c}\text { Concordo } \\
\text { totalmente }\end{array}$ & Concordo & $\begin{array}{c}\text { Em dúvida, mas provavelmente } \\
\text { concordo }\end{array}$ & $\begin{array}{c}\text { Em dúvida, mas provavelmente } \\
\text { discordo }\end{array}$ & $\begin{array}{c}\text { Discordo } \\
\text { totalmente }\end{array}$ \\
\hline 1 & 2 & 3 & 4 & 6 & 5 \\
\hline
\end{tabular}

28. Nossos hospitais psiquiátricos se parecem mais com prisões do que com locais onde pessoas mentalmente doentes possam ser cuidados.

\begin{tabular}{|c|c|c|c|c|c|}
\hline $\begin{array}{l}\text { Concordo } \\
\text { totalmente }\end{array}$ & Concordo & $\begin{array}{l}\text { Em dúvida, mas provavelmente } \\
\text { concordo }\end{array}$ & $\begin{array}{l}\text { Em dúvida, mas provavelmente } \\
\text { discordo }\end{array}$ & Discordo & $\begin{array}{l}\text { Discordo } \\
\text { totalmente }\end{array}$ \\
\hline 1 & 2 & 3 & 4 & 5 & 6 \\
\hline
\end{tabular}

29. Não se deve permitir que uma pessoa internada em hospital psiquiátrico vote.

\begin{tabular}{|c|c|c|c|c|c|}
\hline $\begin{array}{c}\text { 29. Não se deve permitir que uma pessoa internada em hospital psiquiátrico vote. } \\
\text { totalmente }\end{array}$ & Concordo & $\begin{array}{c}\text { Em dúvida, mas provavelmente } \\
\text { concordo }\end{array}$ & $\begin{array}{c}\text { Em dúvida, mas provavelmente } \\
\text { discordo }\end{array}$ & $\begin{array}{c}\text { Discordo } \\
\text { totalmente }\end{array}$ \\
\hline 1 & 2 & 3 & 4 & 6 & 5 \\
\hline
\end{tabular}

30. A doença mental de muitas pessoas é causada pela separação ou divórcio de seus pais durante a infância.

\begin{tabular}{|c|c|c|c|c|c|}
\hline $\begin{array}{c}\text { Concordo } \\
\text { totalmente }\end{array}$ & Concordo & $\begin{array}{c}\text { Em dúvida, mas provavelmente } \\
\text { concordo }\end{array}$ & $\begin{array}{c}\text { Em dúvida, mas provavelmente } \\
\text { discordo }\end{array}$ & $\begin{array}{c}\text { Discordo } \\
\text { totalmente }\end{array}$ \\
\hline 1 & 2 & 3 & 4 & 6 & 5 \\
\hline
\end{tabular}


31. A melhor forma de se lidar com pacientes em hospitais psiquiátricos é mantê-los a portas trancadas.

\begin{tabular}{|c|c|c|c|c|c|}
\hline $\begin{array}{c}\text { Concordo } \\
\text { totalmente }\end{array}$ & Concordo & $\begin{array}{c}\text { Em dúvida, mas provavelmente } \\
\text { concordo }\end{array}$ & $\begin{array}{c}\text { Em dúvida, mas provavelmente } \\
\text { discordo }\end{array}$ & $\begin{array}{c}\text { Discordo } \\
\text { totalmente }\end{array}$ & \begin{tabular}{c} 
Discordo \\
\hline 1
\end{tabular} \\
\hline 1 & 3 & 4 & 6 & 5 \\
\hline
\end{tabular}

32. Tornar-se paciente em um hospital psiquiátrico é tornar-se um fracasso na vida.

\begin{tabular}{|c|c|c|c|c|c|}
\hline $\begin{array}{c}\text { Concordo } \\
\text { totalmente }\end{array}$ & Concordo & $\begin{array}{c}\text { Em dúvida, mas provavelmente } \\
\text { concordo }\end{array}$ & $\begin{array}{c}\text { Em dúvida, mas provavelmente } \\
\text { discordo }\end{array}$ & $\begin{array}{c}\text { Discordo } \\
\text { totalmente }\end{array}$ \\
\hline 1 & 2 & 3 & 4 & 6 & 5 \\
\hline
\end{tabular}

33. Os pacientes de hospitais psiquiátricos devem ter direito a maior privacidade, ou seja, deve haver mais respeito à sua individualidade.

\begin{tabular}{|c|c|c|c|c|c|}
\hline $\begin{array}{c}\text { Concordo } \\
\text { totalmente }\end{array}$ & Concordo & $\begin{array}{c}\text { Em dúvida, mas provavelmente } \\
\text { concordo }\end{array}$ & $\begin{array}{c}\text { Em dúvida, mas provavelmente } \\
\text { discordo }\end{array}$ & $\begin{array}{c}\text { Discordo } \\
\text { totalmente }\end{array}$ \\
\hline 1 & 2 & 3 & 4 & 6 & 5 \\
\hline
\end{tabular}

34. Se um paciente em um hospital psiquiátrico atacar alguém, deve ser punido para que o fato não se repita.

\begin{tabular}{|c|c|c|c|c|c|}
\hline $\begin{array}{c}\text { Concordo } \\
\text { totalmente }\end{array}$ & Concordo & $\begin{array}{c}\text { Em dúvida, mas provavelmente } \\
\text { concordo }\end{array}$ & $\begin{array}{c}\text { Em dúvida, mas provavelmente } \\
\text { discordo }\end{array}$ & $\begin{array}{c}\text { Discordo } \\
\text { totalmente }\end{array}$ & \begin{tabular}{c} 
Discordo \\
\hline 1
\end{tabular} \\
\hline 1 & 3 & 4 & 6 & 5 \\
\hline
\end{tabular}

35. Se filhos de pais normais fossem criados por um casal mentalmente doente, provavelmente tornar-se-iam doentes mentais.

\begin{tabular}{|c|c|c|c|c|c|}
\hline $\begin{array}{c}\text { Concordo } \\
\text { totalmente }\end{array}$ & Concordo & $\begin{array}{c}\text { Em dúvida, mas provavelmente } \\
\text { concordo }\end{array}$ & $\begin{array}{c}\text { Em dúvida, mas provavelmente } \\
\text { discordo }\end{array}$ & $\begin{array}{c}\text { Discordo } \\
\text { totalmente }\end{array}$ & \begin{tabular}{c} 
Discordo \\
\hline 1
\end{tabular} \\
\hline 1 & 3 & 4 & 6 & 5 \\
\hline
\end{tabular}

36. Todo hospital psiquiátrico deve ser cercado por altos muros e ter vigilantes.

\begin{tabular}{|c|c|c|c|c|c|}
\hline $\begin{array}{c}\text { Concordo } \\
\text { totalmente }\end{array}$ & Concordo & $\begin{array}{c}\text { Em dúvida, mas provavelmente } \\
\text { concordo }\end{array}$ & $\begin{array}{c}\text { Em dúvida, mas provavelmente } \\
\text { discordo }\end{array}$ & $\begin{array}{c}\text { Discordo } \\
\text { totalmente }\end{array}$ \\
\hline 1 & 2 & 3 & 4 & 5 & 5 \\
\hline
\end{tabular}

37. Deve ser legalmente permitido que uma mulher se divorcie de seu marido assim que ele seja internado em um hospital psiquiátrico com uma doença mental grave.

\begin{tabular}{|c|c|c|c|c|c|}
\hline $\begin{array}{c}\text { Concordo } \\
\text { totalmente }\end{array}$ & Concordo & $\begin{array}{c}\text { Em dúvida, mas provavelmente } \\
\text { concordo }\end{array}$ & $\begin{array}{c}\text { Em dúvida, mas provavelmente } \\
\text { discordo }\end{array}$ & $\begin{array}{c}\text { Discordo } \\
\text { totalmente }\end{array}$ & \begin{tabular}{c} 
Discordo \\
\hline 1
\end{tabular} \\
\hline 1 & 3 & 4 & 6 & 5 \\
\hline
\end{tabular}

38. As pessoas que estão incapacitadas para o trabalho devido a uma doença mental devem receber auxilio financeiro para a sua manutenção.

\begin{tabular}{|c|c|c|c|c|c|}
\hline $\begin{array}{c}\text { Concordo } \\
\text { totalmente }\end{array}$ & Concordo & $\begin{array}{c}\text { Em dúvida, mas provavelmente } \\
\text { concordo }\end{array}$ & $\begin{array}{c}\text { Em dúvida, mas provavelmente } \\
\text { discordo }\end{array}$ & $\begin{array}{c}\text { Discordo } \\
\text { totalmente }\end{array}$ & \begin{tabular}{c} 
Discordo \\
\hline 1
\end{tabular} \\
\hline
\end{tabular}

39. A doença mental é geralmente causada por alguma doença do sistema nervoso.

\begin{tabular}{|c|c|c|c|c|c|}
\hline $\begin{array}{c}\text { Concordo } \\
\text { totalmente }\end{array}$ & Concordo & $\begin{array}{c}\text { Em dúvida, mas provavelmente } \\
\text { concordo }\end{array}$ & $\begin{array}{c}\text { Em dúvida, mas provavelmente } \\
\text { discordo }\end{array}$ & $\begin{array}{c}\text { Discordo } \\
\text { totalmente }\end{array}$ \\
\hline 1 & 2 & 3 & 4 & 6 \\
\hline
\end{tabular}

40. Os pacientes com doença mental grave deixam de ser realmente humanos.

\begin{tabular}{|c|c|c|c|c|c|}
\hline $\begin{array}{c}\text { Concordo } \\
\text { totalmente }\end{array}$ & Concordo & $\begin{array}{c}\text { Em dúvida, mas provavelmente } \\
\text { concordo }\end{array}$ & $\begin{array}{c}\text { Em dúvida, mas provavelmente } \\
\text { discordo }\end{array}$ & $\begin{array}{c}\text { Discordo } \\
\text { totalmente }\end{array}$ \\
\hline 1 & 2 & 3 & 4 & 6 & 5 \\
\hline
\end{tabular}

41. A maioria das mulheres que já foram pacientes em hospitais psiquiátricos pode ter crianças pequenas entregues a seus cuidados.

\begin{tabular}{|c|c|c|c|c|c|}
\hline $\begin{array}{c}\text { Concordo } \\
\text { totalmente }\end{array}$ & Concordo & $\begin{array}{c}\text { Em dúvida, mas provavelmente } \\
\text { concordo }\end{array}$ & $\begin{array}{c}\text { Em dúvida, mas provavelmente } \\
\text { discordo }\end{array}$ & $\begin{array}{c}\text { Discordo } \\
\text { totalmente }\end{array}$ & \begin{tabular}{c} 
Discordo \\
\hline 1
\end{tabular} \\
\hline
\end{tabular}

42. A maioria dos pacientes em hospitais psiquiátricos não se preocupa com sua aparência.

\begin{tabular}{|c|c|c|c|c|c|}
\hline $\begin{array}{c}\text { Concordo } \\
\text { totalmente }\end{array}$ & Concordo & $\begin{array}{c}\text { Em dúvida, mas provavelmente } \\
\text { concordo }\end{array}$ & $\begin{array}{c}\text { Em dúvida, mas provavelmente } \\
\text { discordo }\end{array}$ & $\begin{array}{c}\text { Discordo } \\
\text { totalmente }\end{array}$ \\
\hline 1 & 2 & 3 & 4 & 6 \\
\hline
\end{tabular}

43. Os professores universitários têm maior probabilidade de se tornarem mentalmente doentes que os comerciantes. 


\begin{tabular}{|c|c|c|c|c|c|}
\hline $\begin{array}{c}\text { Concordo } \\
\text { totalmente }\end{array}$ & Concordo & $\begin{array}{c}\text { Em dúvida, mas provavelmente } \\
\text { concordo }\end{array}$ & $\begin{array}{c}\text { Em dúvida, mas provavelmente } \\
\text { discordo }\end{array}$ & $\begin{array}{c}\text { Discordo } \\
\text { totalmente }\end{array}$ & \begin{tabular}{c} 
Discordo \\
\hline 1
\end{tabular} \\
\hline 1 & 3 & 4 & 6 \\
\hline
\end{tabular}

44. Muitas pessoas que nunca foram pacientes em um hospital psiquiátrico são mentalmente mais doentes do que muitos dos pacientes psiquiátricos hospitalizados.

\begin{tabular}{|c|c|c|c|c|c|}
\hline $\begin{array}{c}\text { Concordo } \\
\text { totalmente }\end{array}$ & Concordo & $\begin{array}{c}\text { Em dúvida, mas provavelmente } \\
\text { concordo }\end{array}$ & $\begin{array}{c}\text { Em dúvida, mas provavelmente } \\
\text { discordo }\end{array}$ & $\begin{array}{c}\text { Discordo } \\
\text { totalmente }\end{array}$ & \begin{tabular}{c} 
Discordo \\
\hline 1
\end{tabular} \\
\hline 1 & 3 & 4 & 6 & 5 \\
\hline
\end{tabular}

45. Embora alguns pacientes psiquiátricos pareçam estar bem, é perigoso esquecer que são mentalmente doentes.

\begin{tabular}{|c|c|c|c|c|c|}
\hline $\begin{array}{c}\text { Concordo } \\
\text { totalmente }\end{array}$ & Concordo & $\begin{array}{c}\text { Em dúvida, mas provavelmente } \\
\text { concordo }\end{array}$ & $\begin{array}{c}\text { Em dúvida, mas provavelmente } \\
\text { discordo }\end{array}$ & $\begin{array}{c}\text { Discordo } \\
\text { totalmente }\end{array}$ & \begin{tabular}{c} 
Discordo \\
\hline 1
\end{tabular} \\
\hline 1 & 3 & 4 & 6 & 5 \\
\hline
\end{tabular}

46. Às vezes a doença mental é uma punição por erros cometidos.

\begin{tabular}{|c|c|c|c|c|c|}
\hline $\begin{array}{c}\text { Concordo } \\
\text { totalmente }\end{array}$ & Concordo & $\begin{array}{c}\text { Em dúvida, mas provavelmente } \\
\text { concordo }\end{array}$ & $\begin{array}{c}\text { Em dúvida, mas provavelmente } \\
\text { discordo }\end{array}$ & $\begin{array}{c}\text { Discordo } \\
\text { totalmente }\end{array}$ & \begin{tabular}{c} 
Discordo \\
\hline 1
\end{tabular} \\
\hline 1 & 3 & 4 & 6 & 5 \\
\hline
\end{tabular}

47. Nossos hospitais psiquiátricos deveriam ser organizados de modo a permitir que o paciente se sentisse como se estivesse em sua própria casa.

\begin{tabular}{|c|c|c|c|c|c|}
\hline $\begin{array}{c}\text { Concordo } \\
\text { totalmente }\end{array}$ & Concordo & $\begin{array}{c}\text { Em dúvida, mas provavelmente } \\
\text { concordo }\end{array}$ & $\begin{array}{c}\text { Em dúvida, mas provavelmente } \\
\text { discordo }\end{array}$ & $\begin{array}{c}\text { Discordo } \\
\text { totalmente }\end{array}$ & \begin{tabular}{c} 
Discordo \\
\hline 1
\end{tabular} \\
\hline 1 & 3 & 4 & 6 & 5 \\
\hline
\end{tabular}

48. Uma das principais causas de doença mental é a falta de força moral ou força de vontade.

\begin{tabular}{|c|c|c|c|c|c|}
\hline $\begin{array}{c}\text { Concordo } \\
\text { totalmente }\end{array}$ & Concordo & $\begin{array}{c}\text { Em dúvida, mas provavelmente } \\
\text { concordo }\end{array}$ & $\begin{array}{c}\text { Em dúvida, mas provavelmente } \\
\text { discordo }\end{array}$ & $\begin{array}{c}\text { Discordo } \\
\text { totalmente }\end{array}$ & \begin{tabular}{c} 
Discordo \\
\hline 1
\end{tabular} \\
\hline 1 & 3 & 4 & 6 & 5 \\
\hline
\end{tabular}

49. Há pouco que possa ser feito pelos pacientes em hospitais psiquiátricos, além de cuidar de que tenham conforto e estejam bem alimentados.

\begin{tabular}{|c|c|c|c|c|c|}
\hline $\begin{array}{c}\text { Concordo } \\
\text { totalmente }\end{array}$ & Concordo & $\begin{array}{c}\text { Em dúvida, mas provavelmente } \\
\text { concordo }\end{array}$ & $\begin{array}{c}\text { Em dúvida, mas provavelmente } \\
\text { discordo }\end{array}$ & $\begin{array}{c}\text { Discordo } \\
\text { totalmente }\end{array}$ & \begin{tabular}{c} 
Discordo \\
\hline 1
\end{tabular} \\
\hline
\end{tabular}

50. Muitos doentes mentais optariam por permanecer no hospital até que estivessem bem, mesmo que o hospital fosse mantido a portas abertas.

\begin{tabular}{|c|c|c|c|c|c|}
\hline $\begin{array}{c}\text { Concordo } \\
\text { totalmente }\end{array}$ & Concordo & $\begin{array}{c}\text { Em dúvida, mas provavelmente } \\
\text { concordo }\end{array}$ & $\begin{array}{c}\text { Em dúvida, mas provavelmente } \\
\text { discordo }\end{array}$ & $\begin{array}{c}\text { Discordo } \\
\text { totalmente }\end{array}$ & \begin{tabular}{c} 
Discordo \\
\hline 1
\end{tabular} \\
\hline 1 & 3 & 4 & 6 & 5 \\
\hline
\end{tabular}

51. Todos os pacientes de um hospital psiquiátrico deveriam ser cirurgicamente impedidos de procriarem.

\begin{tabular}{|c|c|c|c|c|c|}
\hline $\begin{array}{c}\text { Concordo } \\
\text { totalmente }\end{array}$ & Concordo & $\begin{array}{c}\text { Em dúvida, mas provavelmente } \\
\text { concordo }\end{array}$ & $\begin{array}{c}\text { Em dúvida, mas provavelmente } \\
\text { discordo }\end{array}$ & $\begin{array}{c}\text { Discordo } \\
\text { totalmente }\end{array}$ & \begin{tabular}{c} 
Discordo \\
\hline 1
\end{tabular} \\
\hline 1 & 3 & 4 & 6 & 5 \\
\hline
\end{tabular}

Aqui terminamos o nosso questionário. Por favor, verifique se não deixou algum item ou página sem resposta.

Queremos agradecer novamente a contribuição dada ao nosso trabalho, a boa vontade com que fomos recebidos e o tempo despendido por você.

\section{REFERÊNCIAS}

AYUSI GUTIERREZ, J. L.; CALVÉ PÉREZ, A. La psiquiatria em el hospital general. Madri: Paz Monvalvo, 1976.

AYUSI GUTIERREZ, J. L.; SAIZ RUIZ, J. A comaritive study of the psychiatric nurses attitudes towards mental patients. Soc. Psychiatr. Berlin, v. 24, n. 1, p. 47-52, 1978.
BLAYA, M. Grupos operativos hospitalares. In: CONGRESSO LATINO-AMERICANO DE PSICOTERAPIA DE GRUPO, 5., Anais. São Paulo, 1967.

BOTEGA, N. J.; DALGALARRONDO, P. Saúde mental no hospital geral: espaço para o psíquico. São Paulo: Hucitec, 1997.

CANFIELD, A. A. The "sten" scale: a modified C scale. Educ. Psychol. Measur., v. 11, p. 295-297, 
1951.

COHEN, J.; STRUENING, E. L. O. Opinions about illness in the personnel of two large mental hospitals. J. Abnorm. Psychol., Washington, v. 64 , n. 5, p. 349-360, 1962.

KHAN, A.M. Relationship between nurses's opinion about mental illness and experience. Nuns. Res., New York, v. 25, n. 2, p. 136-140, 1976.

KYES, J.; HOFLING, C.K. Conceitos básicos em enfermagem psiquiátrica. Rio de Janeiro: Interamericana, 1985.

LYMAN, H.B. Derived scores: Test scores and what they mean. New Jersey: Prentice - Hall, 1963.

MEYER, L. M. Comparison of attitudes toward mental patient of junior an senior nursing students and their university peers. Nur. Res., New York, v. 22, n. 3, p. 242-245, 1973.

MUNARDI, D. B.; RODRIGUES, A. R. F. Enfermagem e grupos. Goiânia: Ed. AB, 1997.

OSÓRIO, C. S. M. Ambientoterapia: atualização e perspestivas. Rev. Psiquiátri. Porto Alegre, v. 4, n. 3, p. 228-234, 1982.

PEDRÃO, L. J. Avaliação da escala de observação interativa para pacientes psiquiátricos internados aplicada rotineiramente em uma unidade de psiquiatria de hospital geral. Ribeirão Preto, 1997. Tese (Doutorado) - Escola de Enfermagem de Ribeirão Preto, Universidade de São Paulo.

PICHON-RIVIÉRE, H. O processo grupal. 39. ed, São Paulo: Martins Fontes, 1988.

RODRIGUES, A. R. F. Relações interpessoais: humanização da assistência em Saúde Mental. Ribeirão Preto, 1993, p. 245. Tese (Livre Docência) - Escola de Enfermagem de Ribeirão Preto, Universidade de São Paulo.
RODRIGUES, Comparacion de actitudes de estudiantes de medicina brasilenos y espanoles hacia la enfermidade mental. Actas Loso-Esp. Neurol. Psiquiatr. Ci. Afines, v. 20, n. 1, p. 30-41, 1992.

STRUENING, E. L.; COHEN, J. Fatorial invariance and other psychometric characteristics of five opinions about mental illness fators. Educ. Psychol. Measur., v. 23, n. 3, p. 289-298, 1963.

TAYLOR, C. M. Fundamentos de enfermagem psiquiatrica de Mereness. Porto Alegre: Artes Médicas, 1992.
ENDEREÇO DOS AUTORES:

R. Sebastião Marcos Luiz, 1368 Curitiba/PR 82930-060 rrossi@eerp.usp.br 